\title{
Experimental Verification of Seed Transmission of Zucchini yellow mosaic virus
}

H. E. Simmons, Department of Biology, The Pennsylvania State University, University Park, PA 16802; E. C. Holmes, Department of Biology, The Pennsylvania State University, University Park, PA 16802, and Fogarty International Center, National Institutes of Health, Bethesda, MD 20892; F. E. Gildow, Department of Plant Pathology, and M. A. Bothe-Goralczyk and A. G. Stephenson, Department of Biology, The Pennsylvania State University, University Park, PA 16802

\begin{abstract}
Simmons, H. E., Holmes, E. C., Gildow, F. E., Bothe-Goralczyk, M. A., and Stephenson, A. G. 2011. Experimental verification of seed transmission of Zucchini yellow mosaic virus. Plant Dis. 95:751-754.

Within two decades of its discovery, Zucchini yellow mosaic virus (ZYMV) achieved a global distribution. However, whether or not seed transmission occurs in this economically significant crop pathogen is controversial, and the relative impact of seed transmission on the epidemiology of ZYMV remains unclear. Using reverse transcriptionpolymerase chain reaction, we observed a seed transmission rate of $1.6 \%$ in Cucurbita pepo subsp. texana and show that seed-infected $C$. pepo plants are capable of initiating horizontal ZYMV infections, both

mechanically and via an aphid vector (Myzus persicae). We also provide evidence that $\mathrm{ZYMV}$-infected seeds may act as effective viral reservoirs, partially accounting for the current geographic distribution of ZYMV. Finally, the observation that ZYMV infection of $C$. pepo seeds results in virtually symptomless infection, coupled with our finding that an antibody test failed to detect vertically transmitted ZYMV in infected seed, highlights the urgent need to standardize current detection methods for seed infection.
\end{abstract}

Since the discovery of Zucchini yellow mosaic virus (ZYMV) in Italy in 1973, and its subsequent description in 1981 (14), this emerging RNA virus has spread rapidly and achieved an effectively global distribution (5). Although a number of explanations have been put forward to account for the widespread geographic distribution and persistence of this virus, including the international trading of infected fruit, plants, or seeds, as well as overwintering in alternative hosts and noncolonizer aphids, the mechanisms underlying the rapid dissemination and persistence of ZYMV remain unclear (13). ZYMV is a single-stranded positive-sense RNA virus of the family Potyviridae that can result in yellowing and stunting of the plant, as well as severe leaf and fruit deformities that can reduce yields up to $94 \%$ (1). Given that cucurbit (squash, melon, and cucumber) production in the United States alone is estimated to be worth approximately $\$ 1.5$ billion per year (2), the economic significance of this crop pathogen is enormous. Understanding the epidemiology and evolution of ZYMV is therefore central to controlling this devastating crop disease.

Viral transmission generally occurs in one of two ways: horizontally, which is the transmission of the virus between unrelated hosts, or vertically, which is the transmission of the virus from parent to offspring. ZYMV is horizontally transmitted in a nonpersistent manner by at least 26 aphid species (12). Transmission occurs as a result of an interaction between the stylet of the aphid, the helper component protein (HC-Pro), and the conserved DAG (AspAla-Gly) region of the coat protein (CP) (18). However, the current worldwide distribution of ZYMV is unlikely to have resulted from aphid transmission alone, particularly as the aphid vector remains viruliferous for a very limited time period $\left(\sim 5 \mathrm{~h}\right.$ at $\left.21^{\circ} \mathrm{C}\right)$ after acquisition of the virus (6). Hence, it has been suggested that the

Corresponding author: H. E. Simmons, E-mail: hes142@psu.edu

GenBank Accession Numbers for nucleotide sequences are HQ543133 to HQ543139.

Accepted for publication 18 February 2011.

doi:10.1094/PDIS-11-10-0843

(C) 2011 The American Phytopathological Society long-distance spread of ZYMV may be the result of vertical transmission via infected seeds rather than horizontal transmission by aphids $(4,5,7,13,22,24)$. Whether or not seed transmission of ZYMV occurs remains controversial. This controversy is due in part to the fact that the reported rates of seed transmission in cucurbits range from 0 to $18.9 \%(4,5,7,9,13,16,19,20,22,24)$. Accurately determining the rate of seed transmission of ZYMV is of fundamental importance for understanding the epidemiology of this major plant-pathogenic virus and for developing and implementing strategies to control it.

Some of the reported variation in the estimates of seed transmission rates in ZYMV undoubtedly results from differences in detection methods. For instance, using an enzyme-linked immunosorbent assay (ELISA)-based method, Davis and Mizuki (4) found 18\% (246 of 1,299) of Cucurbita pepo (Black Beauty zucchini) seedlings to be infected with ZYMV. Similarly, Fletcher et al. (7), using DAS-ELISA, observed seed transmission rates of $3.5 \%$ for ZYMV in C. maxima Duchesne (buttercup squash). However, their results should be interpreted with caution because they also observed a $2 \%$ transmission rate of ZYMV in their controls (possibly as a result of virus particles remaining on the seed coat). Muller et al. (16) using DAS-ELISA detected ZYMV in two of 1,000 asymptomatic Cucumis sativus L. (cucumber), C. pepo L., and $C$. maxima Duchesne (pumpkin) that grew from seeds from infected plants, while ZYMV was detected in 1.4\% (15 of 1,031) seedlings of $C$. pepo var. styriaca (naked seed pumpkin mutant) using a combination of both DAS-ELISA and reverse transcription-polymerase chain reaction (RT-PCR) (19). More recently, Lecoq et al. (13) mention unpublished data in which no seed transmission of ZYMV was observed in 70,000 seedlings from various Cucurbitaceae. Other studies suggest that there is only minimal, if any, seed transmission of ZYMV in Cucumis melo L. (melon) (9), and that ZYMV transmission through seeds is probably of no epidemiological importance (16).

Finally, interpretations on rates of seed transmission for ZYMV also differ. For instance, Robinson et al. (20) found seed transmission rates of only $0.07 \%$ in various cucurbits and concluded that seed transmission does not occur in ZYMV, while Schrijnwerkers et al. (22) found a seed transmission rate of $0.05 \%$ in C. pepo (zucchini) and concluded that seed transmission does occur in ZYMV. Similarly, Tobias and Palkovics (24) reported symptomatic infec- 
tions of $<0.5 \%$ seeds of ZYMV-infected plants from $C$. pepo var. styriaca (hull-less seeded oil pumpkin seeds) and concluded that seed transmission does occur at very low rates.

To determine what contribution seed transmission has on the epidemiology of ZYMV, we used $C$. pepo subsp. texana (wild gourd) as a model system and measured the seed transmission rate of ZYMV by visual inspection, RT-PCR, and antibody tests (ImmunoStrips; Agdia, Elkhart, IN). Seed transmission of ZYMV is only epidemiologically significant if vertically infected plants are capable of initiating additional infections via horizontal transmission. To test for horizontal transmission, we assayed the ability of the vertically infected plants to initiate infection via mechanical inoculation and tested for the ability of an aphid vector (Myzus persicae (Sulzer)) to nonpersistently transmit ZYMV from vertically infected plants to healthy seedlings.

\section{Materials and Methods}

Seed transmission rate. We harvested approximately 6,000 seeds (count estimated by weight) at the end of the 2008 growing season from ZYMV-infected C. pepo subsp. texana plants growing in four experimental fields at The Pennsylvania State University Agricultural Research Farm at Rock Springs, PA. The 0.4-ha experimental fields were laid out with 180 plants per field with approximately $6 \mathrm{~m}$ between plants. A healthy texana plant that was mechanically inoculated with ZYMV was placed in the middle of each field to serve as a virus source, and the virus was subsequently spread to neighboring plants via aphids. The seeds were extracted in $4 \%$ hydrochloric acid and washed in a $10 \%$ bleach solution to ensure that any viral infection that occurred was not simply the result of virus on the seed coat, but rather the result of embryonic infection. The seeds were then germinated in flats in a greenhouse. At the third true leaf stage, ZYMV infection was determined visually, and if no symptoms were present the seedling was discarded. Based on visual symptoms showing only slight leaf deformations, two out of 3,195 plants had ZYMV, which was verified by RNA extraction, RT-PCR, sequencing, and cloning. In fact, the symptoms were so mild that they could have been easily overlooked or considered to be normal in appearance. We subsequently pooled an additional 281 symptomless seedlings in groups of 10 for a total of 29 groups, 28 with 10 seedlings apiece, and as there was a final single seedling, this was treated as an individual group. These 29 groups were tested for ZYMV via RT-PCR. When a group consisting of 10 seedlings tested positive for infection, this result was taken to mean that one of 10 plants was infected. As this interpretation could have underestimated the number of infected seedlings, our estimate of the seed transmission rate is conservative. Because we knew the proportion of samples that tested negative, we used both the binomial distribution and the Poisson distribution to estimate the probability that more than one seedling would test positive in the same sample. At the end of the 2009 season, we again collected fruits from field plants that had been naturally infected with ZYMV via aphid transmission. Although all of the plants displayed classic visible signs of ZYMV foliar infection such as deformed, stunted leaves with yellow mottling, the majority of the fruits showed no symptoms and appeared healthy. The seeds were extracted and cleaned as described above, and seeds from individual plants were pooled. The seeds were planted in flats in the greenhouse. At the third true leaf stage, a leaf tissue sample was collected and frozen at $-80^{\circ} \mathrm{C}$ for analysis from each of 2,336 seedlings. Samples were pooled into batches of 10 for extraction, cDNA synthesis, and PCR. Two plants that tested positive by RT-PCR were also tested for ZYMV using ImmunoStrips as per the manufacturer's protocol. The ZYMV ImmunoStrip is polyclonal and able to detect a number of isolates, including the CT, USDA, SJBCA, CA, IT, NY, FL, and Z18 strains.

RNA isolation, PCR analysis, cloning, sequencing. RNA was isolated from frozen leaf samples using the RNeasy Plant Mini Kit (Qiagen, Valencia, CA). First-strand cDNA was synthesized from the extracted RNA using the Superscript III First-Strand kit (Invitrogen, Carlsbad, CA) as per the manufacturer's protocol, and the target cDNA was then amplified directly via PCR using Phusion High-Fidelity PCR Master Mix (Finnzymes, Espoo, Finland; distributed by New England Biolabs, Ipswich, MA). PCR amplification was performed for 35 cycles (Step 1: $98^{\circ} \mathrm{C}$ for $1 \mathrm{~min}$, Step 2: $98^{\circ} \mathrm{C}$ for $10 \mathrm{~s}$, Step 3: $64^{\circ} \mathrm{C}$ for $20 \mathrm{~s}$ (minus $1^{\circ} \mathrm{C}$ every cycle), Step 4: $72^{\circ} \mathrm{C}$ for $40 \mathrm{~s}$, Step 5: cycle to step 2 for 2 cycles, Step 6: $98^{\circ} \mathrm{C}$ for $10 \mathrm{~s}$, Step 7: $62^{\circ} \mathrm{C}$ for $20 \mathrm{~s}$, Step $8: 72^{\circ} \mathrm{C}$ for $40 \mathrm{~s}$, Step 9: cycle to step 6 for 31 cycles) followed by a final extension for 5 min at $72^{\circ} \mathrm{C}$. The coat protein $(\mathrm{CP})$ specific primers used for the cDNA synthesis and PCR were: forward: AAGTGAATTGGCACG CTA; reverse: CGGTAAATATTAGAATTACGTCG.

To verify that the PCR product was indeed ZYMV, four samples were submitted for sequencing at the Penn State Genomics Core Facility (The Pennsylvania State University, University Park, PA). Each sample was purified with the QIAprep Spin Miniprep Kit (Qiagen). Two samples were cloned using the TOPO TA Cloning Kit (Invitrogen) prior to which each sample was purified using QIAquick PCR Purification Kit (Qiagen) and an A overhang was added to each sample. Approximately 40 clones were submitted from each sample for sequencing. To ensure that mutations were valid, each clone was sequenced in forward and reverse, and manually aligned in the Se-Al (2.0a11) package kindly provided by Andrew Rambaut (University of Edinburgh, UK). Any mutations occurring in only one direction were discarded. This resulted in 71 reliably sequenced clones. The sequences were then trimmed to cover the majority of the $\mathrm{CP}$ region: from the $\mathrm{CP}$ start codon to nucleotide (nt) 773. T7 forward and M13 reverse primers were used for clone sequencing. All sequences generated have been submitted to GenBank and assigned accession numbers (HQ543133 to HQ543139).

Mechanical inoculation. To determine if mechanical transmission can occur from seed-infected plants, we grew six healthy seedlings (noninfection determined via RT-PCR), which we mechanically inoculated with ZYMV-infected tissue from three vertically infected plants. Each infected plant was used to inoculate two healthy seedlings apiece. A $3 \mathrm{~cm}^{2}$ piece of infected leaf tissue was ground in liquid nitrogen prior to being diluted in a phosphate buffer $\left(0.1 \mathrm{M} \mathrm{Na}_{2} \mathrm{H} / \mathrm{KH}_{2} \mathrm{PO}_{4}\right.$ buffer $)$ in a 1:3 ratio. Carborundum powder was dusted on the surface of the leaf, and the inoculum was then applied with a pestle to the leaf surface.

Horizontal transmission from vertically infected plants. We used Myzus persicae to determine if an aphid vector could transmit the virus from a vertically infected plant to healthy seedlings. As a positive control, we assayed a mechanically inoculated infected plant that displayed severe ZYMV symptoms. A leaf was cut into seven portions, and $\sim 25$ aphids apiece were allowed to feed on six of these in the dark for $30 \mathrm{~min}$, the seventh served as a negative control. The leaf portions were then placed on noninfected seedlings (noninfection was checked by RT-PCR) at the first true leaf stage, and these plants were left overnight. The following day, the plants were sprayed with Endeavor (pymetrozine) (Syngenta, Guelph, ON) diluted per the manufacturer's protocol (0.34 g/liter) and applied at a rate of 1 liter per $46.5 \mathrm{~m}^{2}$ to kill the aphid populations, and the seedlings were left in the spray chamber overnight before being returned to an aphid-free greenhouse. After approximately 3 weeks, a leaf sample was collected from each seedling, and infection was determined by RT-PCR. The same procedure as described above was then used to test if horizontal transmission could occur from seven seed-infected plants using 10 to 60 aphids per leaf portion. Each plant was used to infect six healthy seedlings (noninfection was checked by RT-PCR), with an additional healthy plant serving as a control for a total of 42 seedlings.

\section{Results}

ImmunoStrips testing. The two seed-infected plants that tested positive for ZYMV via RT-PCR tested negative using an antibody test (ImmunoStrips from Agdia). In contrast, the mechanically inoculated positive control plant tested positive using the same test.

Seed transmission rate. In 2008, two individual seedlings and four of $281(1.42 \%)$ samples were infected with ZYMV (verified 
by RT-PCR). In 2009, 36 of 2,336 (1.54\%) were infected. Hence, a total of 42 of 2,619 samples, or $1.6 \%$, were infected by seed transmission. Using a binomial distribution, we estimated the probability that an individual seedling would test positive to be $1.66 \%$, while under a Poisson distribution we estimated the same probability to be $1.67 \%$. Thus, we believe that our estimate of a seed transmission rate of $1.6 \%$ accurately reflects the data.

Horizontal transmission from vertically infected plants. We used three seed-infected plants to mechanically inoculate a total of six healthy seedlings (two apiece). From these, we found four $(66.67 \%)$ ZYMV-infected seedlings using RT-PCR.

When seven ZYMV-infected plants derived from infected seed were used as source plants for the aphid transmission tests, the number of seedlings subsequently virus inoculated by the aphids was three out of $42(7.14 \%)$. This seedling infection rate of $7.14 \%$ was verified by RT-RCR, and none of seven control plants fed on by nonviruliferous aphids became infected. In contrast, when one mechanically infected ZYMV was used as a source plant for an aphid transmission test, four of the eight (50\%) seedlings became infected.

Genetic diversity of ZYMV. We generated a total of 71 coat protein $(\mathrm{CP})$ clones from two vertically transmitted plants. Within this sample we found a total of seven mutations, three from one plant (designated seed-2 (S2)) and four from the other (S1). Five of the mutations were singletons (i.e., only observed once in the alignment), and the other was observed in two clones from the same plant (S1). Four mutations were synonymous and three were non-synonymous. A minimum spanning tree, displaying the mutations observed, how they differed from the consensus, as well as a marked absence of phylogenetic structure (i.e., all mutations are one step away from the consensus), was estimated using the statistical parsimony approach available in the TCS 1.21 program (3) (Fig. 1).

It is theoretically possible that the sequences we obtained could be the result of escaped $\mathrm{CP}$ transgenes from deregulated transgenic squash rather than due to seed infections (H. Lecoq, personal communication). However, after cloning and sequencing two of the ZYMV samples, we found that all 71 clone sequences contained 22 amino acids from the protein immediately preceding the $\mathrm{CP}$ (the nuclear inclusion $\mathrm{b}$ ). As the transgene consists of the $\mathrm{CP}$ alone, sequencing a portion of the nuclear inclusion $b$ precludes the possibility that the obtained sequences were derived from an escaped transgene.

\section{Discussion}

We observed a seed transmission rate of $1.6 \%$ for ZYMV in $C$. pepo subsp. texana, as well as evidence that vertically infected plants can act as reservoirs for horizontal transmission. This rate is theoretically high enough for infected seeds to constitute a viable route by which ZYMV epidemics are initiated and hence may be partially responsible for the current geographic distribution of this devastating crop pathogen. Indeed, trace seed infection (0.001) in lettuce mosaic potyvirus has been shown to be sufficient to affect lettuce production due to the subsequent spread of the virus by aphids (11). We therefore believe it is plausible that a seed transmission rate of $1.6 \%$ may be able to initiate yearly epidemics. Also of note is that the DAG motif, which is known to be involved in aphid transmission (8), was not mutated in any of the cloned sequences.

Notably, the infected plants were essentially symptomless. Other than the occasional leaf curling on the first true leaves, which could also occur as the result of mechanical damage when emerging from the seed coat, the plants looked healthy and displayed no mottling, yellowing, or stunting as normally seen with ZYMV infection. This finding may account for the low transmission rates reported by authors who used visual inspection as their primary ZYMV detection method, thereby leading to an underestimation of the true transmission rate. For example, Gleason (9) determined infection based on visual symptoms and reported that only three of $6,800 C$. melo (melon) seedlings displayed the typical ZYMV symptoms of foliar distortion, mosaic and stunting. The lack of obvious viral symptoms also implies that it may be difficult to identify the source of a ZYMV epidemic. In addition, it is possible that healthy-appearing, seed-infected seedlings might be involved in the global spread of the virus. Lecoq et al. (13) demonstrated that melon fruits displaying light disease symptoms of ZYMV infection were capable of transmitting virus via aphids at a $5 \%$ rate. It is possible that apparently healthy looking fruits may also be instrumental in disseminating this virus. However, we previously determined a very strong spatial clustering of ZYMV by country of

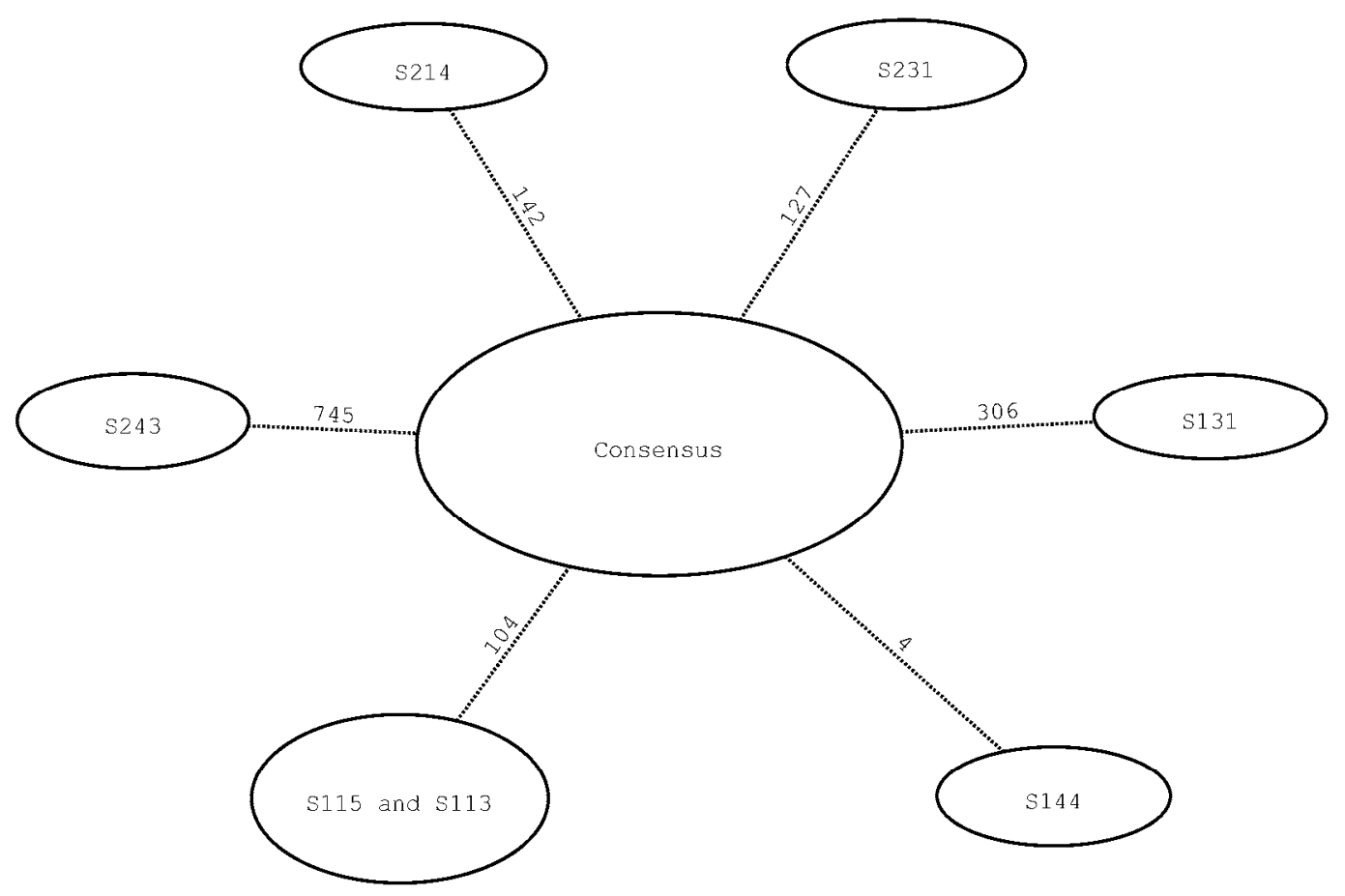

Fig. 1. Minimum-spanning tree of the seed clones. Numbers along branches represent the nucleotide position at which each mutation occurred. Number of clones with a particular mutation is one unless otherwise noted within the oval. S1 and S2 designate seed samples one and two, and the next two digits the clone number. 
origin (23). This suggests that although there is international gene flow of ZYMV, it does not completely disrupt biogeographic structure, which is itself more suggestive of intermittent gene flow via the international seed trade than seed transmission via cultivated cucurbits.

Infected seed as a reservoir of ZYMV is further supported by the observations that overwintering sources of ZYMV are scarce, especially in temperate regions (13), and there are few if any alternative hosts of ZYMV (19). In addition, Schrijnwerkers et al. (22) found that seed transmission rates tend to vary depending upon the age at which the plant becomes infected with ZYMV, with plants infected at an earlier growth stage producing more infected seed. Thus, reservoirs of ZYMV may not remain constant over time, which would explain the observation that ZYMV epidemics often skip years $(10,13,15,21)$

That the ImmunoStrips tested negative while we were able to detect ZYMV via RT-PCR may help to explain the conflicting vertical transmission rates found in the literature. Given that the immunostrip is polyclonal, it is unlikely that the negative result is due to strain differences. As we only detected a small number of mutations in the clones, it is possible that the inability of the ImmunoStrips to detect ZYMV may be the result of lower virus titers in the seed-infected samples. However, as we only sequenced 773 nucleotides (out of 849 from the CP start codon to the CP stop codon) of the $\mathrm{CP}$, it is possible that $\mathrm{CP}$ gene may have accumulated a sufficient number of mutational differences that antibodies are no longer able to react with it.

The failure to detect vertically transmitted ZYMV using nonPCR techniques coupled with our findings that vertically infected ZYMV can be horizontally transmitted has implications for the international seed trade. Currently, three major organizations publish standardized testing methods for seed health: International Seed Testing association (ISTA), International Seed Health Initiative (ISHI), and in the U.S. the National Seed Health System (NSHS). Of the 14 approved methods for virus detection in seeds, three use indicator plants while the remainder use ELISA testing (17). We therefore suggest that one of the primary objectives for control strategies for ZYMV should be the establishment of standardized testing protocol for the detection of vertical infection in seeds.

\section{Acknowledgments}

We thank William Sackett for his invaluable advice and assistance with the aphid transmission tests. Sarah Scanlon and Kelly Wall for field, greenhouse, and lab assistance, Tony Omeis for greenhouse assistance as well as the use of the Biology Greenhouse, and R. Oberheim and his staff for use of the Horticulture Farm at the PSU Agriculture Experiment Station at Rock Springs, PA. This work was supported by NSF Grant DEB02-35217 and by grants 2008-3530204577 and 2009-33120-20093 from the USDA National Institute of Food and Agriculture.

\section{Literature Cited}

1. Blua, M., and Perring, T. 1989. Effect of zucchini yellow mosaic virus on development and yield of cantaloupe (cucumis melo). Plant Dis. 73:317320 .
2. Cantliffe, D. J., Shaw, N. L., and Stoffella P. J. 2007. Current trends in cucurbit production in the U.S. Acta. Hortic. 731:473-478.

3. Clement, M., Posada, D., and Crandall, K. A. 2000. TCS: A computer program to estimate gene genealogies. Mol. Ecol. 9:1657-1660.

4. Davis, R. F., and Mizuki, M. K. 1986. Seed transmission of zucchini yellow mosaic virus in squash. (Abstr.) Phytopathology 76:1073.

5. Debiez, C., and Lecoq, H. 1997. Zucchini yellow mosaic virus. Plant Pathol. 46: 809-829.

6. Fereres, A., Blua, M. J., and Perring, T. M. 1992. Retention and transmission characteristics of Zucchini yellow mosaic virus by Aphis gossypii and Myzus persicae (Homoptera: Aphididae). J. Econ. Entomol. 85:759-765.

7. Fletcher, J. D., Wallace, A. R., and Rogers, B. T. 2000. Potyviruses in New Zealand butternut squash (Cucurbita maxima Duch.): Yield and quality effects of ZYMV and WMV2 virus infections. N.Z. J. Crop Hortic. Sci. 28:17-26.

8. Gal-On, A. 2007. Zucchini yellow mosaic virus: Insect transmission and pathogenicity - The tails of two proteins. Mol. Plant Pathol. 8:139-150.

9. Gleason, L. 1990. Absence of transmission of Zucchini yellow mosaic virus from seeds of pumpkin. Plant Dis. 74:828.

10. Grafton-Cardwell, E. E., Perring, T. M., Smith, R. F., Valencia, J., and Farrar, C. A. (1996). Occurrence of mosaic viruses in melons in the Central Valley of California. Plant Dis. 80:1092-1097.

11. Johansen, E., Edwards, M. C., and Hampton, R. O. 1994. Seed transmission of viruses: Current perspectives. Annu. Rev. Phytopathol. 32:363-386.

12. Katis, N. I., Tsitsipsi, J. A., Lykouressis, D. P., Papapanayotou, A., Kokinis, G. M., Perdikis, D. C., and Manoussopoulos, I. N. 2006. Transmission of Zucchini yellow mosaic virus by colonizing and non-colonizing aphids in Greece and new aphid vectors of the virus. J. Phytopathol. 154:293-302.

13. Lecoq, H., Desbiez, C., Wipf-Scheibel, C., and Girard, M. 2003. Potential involvement of melon fruit in the long distance dissemination of cucurbit potyviruses. Plant Dis. 87:955-959.

14. Lisa, V., Boccardo, G., D'Agostino, G., Dellavalle, G., and D'Aquilio, M. 1981. Characterization of a potyvirus that causes Zucchini yellow mosaic. Phytopathology 71:667-672.

15. Luis-Atreaga, M., Alvarez, J. M., Alonso-Prados, J. L., Bernal, J. J., GarciaArenal, F., Lavina, A., Batlle, A., and Moriones, E. 1998. Occurrence, distribution, and relative incidence of mosaic viruses infecting field-grown melon in Spain. Plant Dis. 82:979-982.

16. Muller, C., Brother, H., Von Bargen, S., and Buttner, C. 2006. Zucchini yellow mosaic virus - Incidence and sources of virus infection in fieldgrown cucumbers and pumpkins in the Spreewald, Germany. J. Plant Dis. Prot. 113:252-258.

17. Munkvold, G. P. 2009. Seed pathology progress in academia and industry. Annu. Rev. Phytopathol. 47:285-311.

18. Pirone, T. P., and Blanc, S. 1996. Helper-dependent vector transmission of plant viruses. Annu. Rev. Phytopathol. 34:227-247.

19. Riedle-Bauer, M., Suarez, B., and Reinprecht, H. J. 2002. Seed transmission and natural reservoirs of Zucchini yellow mosaic virus in Cucurbita pepo var. styriaca. J. Plant Dis. Prot. 109:200-206.

20. Robinson, R. W., Provvidenti, R., and Shail, J. W. 1993. Tests for seedborne transmission of Zucchini yellow mosaic virus. HortScience 28:694-696.

21. Rubies-Antonell, C., Ballante, M., and Turina, M. 1996. Virus infection in melon crops in Central-Northern Italy. Inform. Fitopathol. 7-8:6-10.

22. Schrijnwerkers, C. C. F. M., Huijberts, N., and Bos, L. 1991. Zucchini yellow mosaic virus; Two outbreaks in the Netherlands and seed transmissibility. Neth. J. Plant Pathol. 97:187-191.

23. Simmons, H. E., Holmes, E. C., and Stephenson, A. G. 2008. Rapid evolutionary dynamics of zucchini yellow mosaic virus. J. Gen. Virol. 89:10811085

24. Tobias, I., and Palkovics, L. 2003. Characterization of Hungarian isolates of zucchini yellow mosaic virus (ZYMV, potyvirus) transmitted by seeds of Curcubita pepo var. styriaca. Pest Manag. Sci. 59:493-497. 